\title{
Increased serum aldosterone in diabetic pregnancy
}

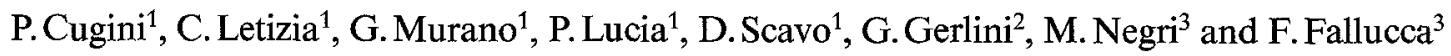 \\ ${ }^{1}$ Cattedra di Patologia Medica I, ${ }^{2}$ Istituto di Puericultura, and ${ }^{3}$ Cattedra di Diabetologia, University of Rome "La Sapienza", Italy
}

\begin{abstract}
Summary. Serum levels of aldosterone and cortisol were measured by radioimmunoassay in 15 patients with gestational diabetes, in 18 patients with Type 1 (insulin-dependent) diabetes, in 36 pregnant control women and in 10 non-pregnant control women. All subjects, on habitual sodium and potassium intake, were sampled in a supine position at 09.00 hours. Pregnant women were examined twice, during gestational week 32-34 and at delivery. Serum levels of aldosterone and cortisol were also measured in the umbilical cord blood of newborn babies of these diabetic and non-diabetic mothers.
\end{abstract}

Serum levels of aldosterone in both gestational and Type 1 pregnant diabetic women were found to be consistently above the reference values of non-diabetic pregnant women. Abnormal serum levels of aldosterone were also observed in newborn infants of diabetic mothers. In contrast, serum levels of cortisol were not increased.

Key words: Adrenal glands, aldosterone, diabetes mellitus, pregnancy.
Several studies have reported increased plasma aldosterone levels in pregnancy [1]. Particularly elevated plasma aldosterone levels have been demonstrated in pregnant women with diabetes mellitus [2].

We have measured serum aldosterone levels in nonketotic diabetic women in late pregnancy. The diabetic pregnant women included in the study were affected either by gestational diabetes (impaired glucose tolerance or hyperglycaemia which appeared during pregnancy) or Type 1 diabetes mellitus. Normoglycaemic non-pregnant and pregnant women were also studied as reference groups.

\section{Subjects and methods}

The following four groups of women were studied: group I, 10 nonpregnant control women; group II, 36 pregnant control women; group III, 15 pregnant women with gestational diabetes; and group IV, 18 Type 1 diabetic pregnant women. (Table 1)

Serum aldosterone and cortisol were measured in all the pregnant mothers in late gestation (32-34 weeks), at delivery ( $2 \mathrm{~h}$ before Caesarian section or at the beginning of labour) and in cord blood of their newborns.

Maternal blood samples were collected from an antecubital vein at 09.00 hours in fasting $(10-12 \mathrm{~h})$ subjects who had remained on habitual sodium and potassium intake since the 30 th week of gestation or earlier. Samples were collected only while the subjects were in a sodium and potassium balance (difference between dietary intake and $24 \mathrm{~h}$ urinary excretion rate less than $20 \%$ ). Effects of transient hypoglycaemia, dehydration, haemodilution and/or ketosis were excluded.

Non-pregnant control women (group I) in sodium balance and in the follicular phase of their menstrual cycle were also sampled at 09.00 hours in the fasting state $(10-12 \mathrm{~h})$ after being recumbent for at least $8 \mathrm{~h}$.

Gestational (group III) and Type 1 (group IV) diabetic pregnant women included in the study all had a satisfactory metabolic control evaluated on the basis of the mean monthly three daily blood glucose values and on the evaluation of index score [3], taking into account episodes of hypoglycaemia and acetonuria in addition to blood glucose levels throughout the pregnancy.

Serum aldosterone and cortisol concentrations were measured using the commercial kits of CEA-IRE-Sorin (Saluggia, Vercelli, Italy) and of the Immune Nuclear Corporation (Stillwater, Minn USA).

\section{Statistical analysis}

Differences between groups were analyzed using non-parametric statistics (Mann-Whitney test, Wilcoxon test). A $p$ value of $\leqslant 0.05$ was considered statistically significant.

\section{Results}

Serum aldosterone and cortisol values obtained in pregnant women and newborns are shown in Table 2.

Serum aldosterone and cortisol levels in control non-pregnant women were respectively equal to $7.2 \pm$ 
$1.8 \mathrm{ng} / \mathrm{dl}$ and $12.2 \pm 1.13 \mu \mathrm{g} / \mathrm{dl}$, being significantly lower $(p<0.01$ and $p<0.001$, respectively) than those observed in control pregnant women.

In late gestation, serum aldosterone levels were significantly higher $(p<0.05)$ in the gestational diabetic and Type 1 patients than in control subjects.

No significant differences were found between the two groups of diabetic patients. At delivery, serum aldosterone values were further increased in control pregnant women $(p<0.001)$ and gestational diabetic pregnant women $(p<0.01)$; the rise in Type 1 diabetic pregnant women was not significant.

The measurements in cord blood showed that serum aldosterone levels of infants of diabetic mothers were significantly higher $(p<0.01 ; p<0.001)$ than those observed in control infants.

No significant difference was detected for serum cortisol levels in diabetic and non-diabetic pregnant women and their newborn babies.

No difference in systolic or diastolic blood pressure was found between the four groups of patients studied.

\section{Discussion}

The results of our study confirm that pregnancy is characterized by increased levels of circulating aldosterone and cortisol.

A further and significant increase in serum aldosterone, but not in serum cortisol, levels during pregnancy is observed when pregnancy is complicated by both gestational or Type 1 diabetes. Serum aldosterone levels, but not serum cortisol concentrations are in cord blood of infants of diabetic mothers is also significantly higher than normal.

It is well known that angiotension II and ACTH [4], sodium and potassium [5], growth hormone [6], opiate peptides [7], somatostatin [8], dopamine [9], histamine [10] and serotonin [11] are involved in the control of aldosterone levels. It is not surprising that one or more of these regulatory factors could play a role in the pathogenesis of raised serum aldosterone levels during pregnancy complicated by diabetes mellitus.

The excess of aldosterone in diabetic mothers and their infants is of interest not only for its pathophysiological implications but also in clinical terms.

Bearing in mind the maternal-fetal pathology, it is reasonable that any condition which facilitates sodium retention should be regarded as an event playing an unfavourable role on hypertension, pre-eclampsia and eclampsia, renal diseases, cardiovascular complications, polydramnios and other pathological conditions which are frequently observed in diabetic pregnancy.

\section{References}

1. Cugini P, Centanni M, Salandi E, Scavo D, Dino N, Dolciotti G, Caserta D, Bologna U (1982) Inactive and active renin, aldosterone and cortisol in puerpera and newborn. Clin Exp Obst Gynecol 9: 226-232 
Table 2. Serum aldosterone and cortisol levels measured in pregnant control women, in pregnant women with gestational or Type 1 diabetes mellitus, and in all newborn babies

\begin{tabular}{|c|c|c|c|c|}
\hline Group & Variable & \multicolumn{3}{|l|}{ Conditions } \\
\hline \multirow[t]{2}{*}{$\begin{array}{l}\text { II. Pregnant control } \\
\text { women } \\
(n=36)\end{array}$} & $\begin{array}{l}\text { Serum aldosterone } \\
(\mathrm{ng} / \mathrm{dl})\end{array}$ & $36.2 \pm 5.0$ & $93.4 \pm 7.8$ & $104.7 \pm 8.2$ \\
\hline & $\begin{array}{l}\text { Serum cortisol } \\
(\mu \mathrm{g} / \mathrm{dl})\end{array}$ & $51.4 \pm 1.77$ & $53.2 \pm 1.2$ & $56.4 \pm 5.64$ \\
\hline & $\begin{array}{l}\text { Serum cortisol } \\
(\mu \mathrm{g} / \mathrm{dl})\end{array}$ & $50.6 \pm 1.15$ & $51.3 \pm 1.3$ & $52.0 \pm 9.18$ \\
\hline
\end{tabular}

2. Jadoul FAC, Broughton Pipkin F, Lamming GD (1982) Changes in the renin angiotensin-aldosterone system in normotensive primigravidas in the four days after normal spontaneous delivery. Br Obstet Gynaecol 89: 633-639

3. Fallucca F, Gargiulo P, Troili F, Zicari D, Pimpinella G, Maldonato A, Maggi E, Gerlini G, Pachì A (1985) Amniotic fluid insulin, $\mathrm{C}$-peptide concentrations and fetal morbidity in infants of diabetic mothers. Ann J Obstet Gynecol 153: 534-540

4. Kaplan NM, Bartter FC (1962) The effect of ACTH, renin, angiotensin II and various precursors on biosynthesis of aldosterone by adrenal slices. J Clin Invest 41: 715-724

5. Cannon PJ, Ames PR, Laragh JH (1966) Relation between potassium and aldosterone secretion in normal subjects and in patients with hypertensive or renal disease. J Clin Invest 45: 865-879

6. Venning EH, Lucis OJ (1980) Effect of growth hormone on the biosynthesis of aldosterone in rat. Endocrinology 70: 486-491

7. Matsuoka H, Mulrow PJ, Franco-Saenz R, Li CH (1980) Effects of $\beta$-lipotropin on aldosterone production in rats. Clin Sci 59 [Supp1 6]: 91-94

8. Boscaro M, Scaroni C, Edwards CRW, Mantero F (1982) Inhibitory effect of somatostatin on aldosterone response to angiotensin II in vitro studies. J Endocrinol Invest 5: 173-177
9. Sovers JR, Tuck ML, Barret J, Sambhi MP, Colub MS (1980) Dopaminergic control of aldosterone secretion is independent of the renin-angiotensin system in rats. Clin Sci 50:101-103

10. Pedrinelli R, Ungenti P, Salvetti A (1981) Il ruolo dei recettori istaminergici nel controllo della secrezione di aldosterone: effetto della cimetidina nel sistema renina-aldosterone in pazienti ipertesi. J Endocrinol Invest 4 [Suppl 1]: 239-241

11. Muller S, Ziegel WH (1968) Stimulation of aldosterone biosynthesis in vitro by serotonin. Acta Endocrinol (KBH) 59: 23-27

Received: 7 January 1986

and in revised form: 30 January 1987

Professor Pietro Cugini

c/o II Clinica Medica

Policlinico Umberto I

I-00161 Roma

Italy 